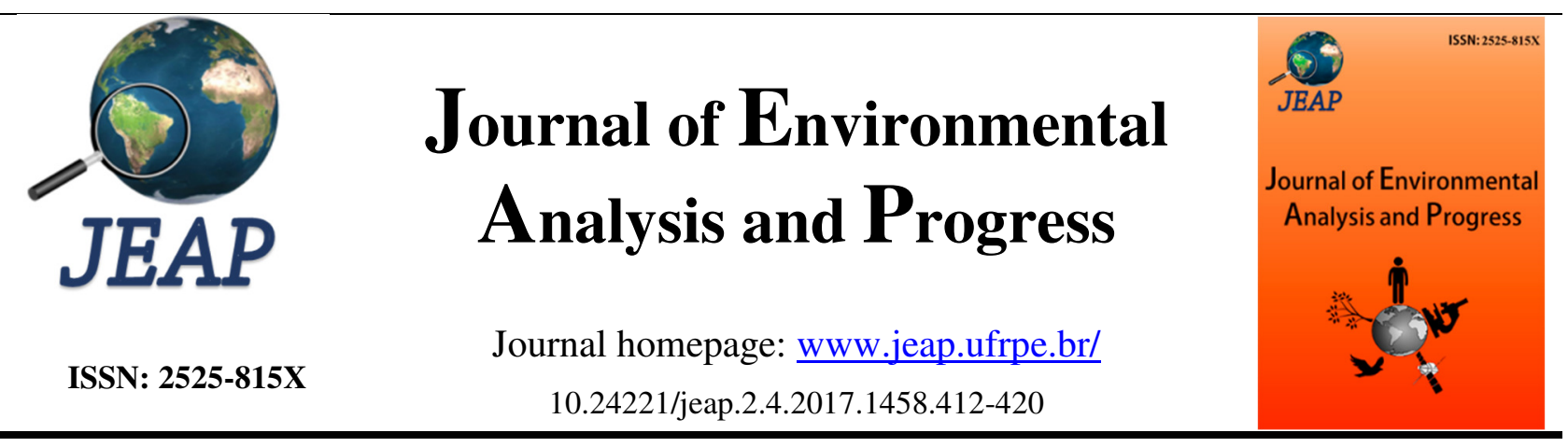

\title{
Temperatura influenciando a germinação de sementes de Piptadenia moniliformis submetidas a superação de dormência
}

\section{Temperature influencing the germination of seeds of Piptadenia moniliformis submitted to the dormancy breakdown}

Joyce Naiara da Silva ${ }^{\mathrm{a}}$, Monalisa Alves Diniz da Silva Camargo Pinto ${ }^{\mathrm{a}}$, Ana Karlla Penna Rocha ${ }^{\mathrm{a}}$, Andressa dos Santos Freire ${ }^{a}$, Larissa de Sá Gomes Leal ${ }^{\mathrm{a}}$

${ }^{\text {a }}$ Universidade Federal Rural de Pernambuco-UFRPE, Unidade Acadêmica de Serra Talhada-UAST, Av. Gregório Ferraz Nogueira, s/n, José Tomé de Souza Ramos, Serra Talhada, Pernambuco. CEP: 56909-535. E-mail: joicenaiara@hotmail.com, monallyysa@yahoo.com.br, karllapenna@hotmail.com, andressa-freire@outlook.com, larissa.leal04@hotmail.com.

\section{A R T I C L E I N F O}

Recebido 30 Jun 2017

Aceito 11 Ago 2017

Publicado 15 Ago 2017

\begin{abstract}
A B S T R A C T
There is reduced information about seed requirements regarding the effects of temperature and light on germination, especially for species typical of secondary vegetation. This study aimed to evaluate the germination and initial development of the angico-de-bezerro seedlings in three sowing periods. The experiment was conducted at UFRPE-UAST from February to April 2017; the design was completely randomized in a $3 \times 5$ factorial scheme (sowing times $\mathrm{x}$ treatments to dormancy breakdown). The seeds were submitted to the previous treatments to dormancy breakdown: $\mathrm{T} 1$ = control - intact seeds; $\mathrm{T} 2$ = immersion in acid in concentrated sulfuric acid for 20 minutes; T3 = immersion in sodium hypochlorite for 6 hours; T4 $=$ immersion in sodium hypochlorite for 12 hours; $\mathrm{T} 5=$ immersion in sodium hypochlorite for 24 hours. Seeds occurred on February 22, March 8 and March 22, 2017. Parameters related to germination and initial seedling development were evaluated. The treatments T2 and T3 provided greater emergence of the seedlings, but there was no difference for the methods of dormancy breakdown over the length of the aerial part and the root system. In general, calf angus seeds showed better emergence percentage results when sown on March 22, when the temperature of the seedlings was better during the 21 days after the beginning of the sowing date. Although it had a better development in the last season, however, the temperature variation observed between the sowing times did not provide differences for the length of the root system.
\end{abstract}

Keywords: Angico-de-bezerro, forest species, initial development.

\section{R E S U M O}

É escasso o conhecimento das exigências das sementes quanto aos efeitos da temperatura e da luz para a germinação, especialmente para as espécies típicas de vegetação secundária. Esse estudo objetivou avaliar a germinação e $\quad 0$ desenvolvimento inicial das plântulas de angico-de-bezerro em três períodos de semeadura. O experimento foi conduzido na UFRPE-UAST nos meses de fevereiro a abril de 2017, o delineamento utilizado foi o inteiramente casualizado em esquema fatorial 3 x 5 (épocas de semeadura x tratamentos de quebra de dormência). As sementes foram submetidas aos tratamentos prévios de quebra de dormência: $\mathrm{T} 1=$ testemunha - sementes intactas; T2 = imersão em ácido em ácido sulfúrico concentrado por 20 minutos; T3 = imersão em hipoclorito de sódio por seis horas; T4 = imersão em hipoclorito de sódio por 12 horas; T5 = imersão em hipoclorito de 
sódio por 24 horas. As semeaduras ocorreram em 22 de fevereiro, 08 de março e 22 de março de 2017. Foram avaliados parâmetros relacionados à germinação e ao desenvolvimento inicial das plântulas. Os tratamentos T2 e T3 propiciaram maior emergência das plântulas, mas não houve diferença para os métodos de quebra de dormência quanto ao comprimento da parte aérea e do sistema radicular. De um modo geral, as sementes de angico de bezerro apresentaram melhores resultados de porcentagem de emergência quando semeadas no dia 22 de março, cuja temperatura estava mais amena durante os 21 dias após a data de semeadura, quanto ao comprimento da parte aérea o mesmo teve um melhor desenvolvimento na última época, entretanto, a variação de temperatura observada entre as épocas de semeadura não proporcionou diferenças para o comprimento do sistema radicular.

Palavras-Chave: Angico-de-bezerro, espécie florestal, desenvolvimento inicial.

\section{Introdução}

Devido a necessidade de recuperação de áreas degradadas, nos últimos anos tem se intensificado o interesse na propagação de espécies florestais nativas, devido à ênfase atual nos problemas ambientais. Entretanto, não há informação disponível sobre o manejo e análise das sementes para a maioria dessas espécies, de modo a fornecer dados que possam caracterizar seus atributos físicos e fisiológicos. Há necessidade de obter informações básicas sobre a germinação, o cultivo e a potencialidade dessas espécies nativas, visando sua utilização para os mais diversos fins (Araújo Neto et al., 2003).

A espécie Piptadenia moniliformis Benth., conhecida como angico-de-bezerro, é uma árvore de 4 a 9 metros de altura, pertencente à família das leguminosas, nativa do nordeste brasileiro. Sua madeira é pesada, com textura média, média resistência mecânica e boa durabilidade natural. Em função de possuir pequenas dimensões no diâmetro do caule e ramos, é empregada em pequenas obras da construção civil, marcenaria leve e fabricação de carvão. É uma espécie rústica e de rápido crescimento, portanto, indicada para a composição de reflorestamentos heterogêneos com fins preservacionistas (Lorenzi, 2002).

Considerando as espécies tropicais, Leal Filho \& Borges (1992) salientaram que muito pouco se conhece sobre as exigências das sementes quanto aos efeitos da temperatura e da luz para a germinação, principalmente para as espécies típicas de vegetação secundária. A germinação, por ser um processo que envolve uma série de reações bioquímicas, torna-se diretamente dependente da temperatura. Como em qualquer reação química, existe uma temperatura ótima na qual o processo se realiza mais rápido e eficientemente, sendo variável para as diversas espécies (Bewley \& Black, 1994; Araújo Neto et al., 2003). A temperatura pode regular a germinação de três maneiras: determinando a capacidade e taxa de germinação; impedindo uma a dormência primária ou secundária e induzindo uma dormência secundária (Bewley \& Black, 1994).
Devido a importância da presença do angico de bezerro para as regiões semiáridas, esse estudo objetivou avaliar a germinação e o desenvolvimento das plântulas, utilizando diferentes métodos para a quebra da dormência das sementes.

\section{Material e Métodos}

Dados do experimento

$O$ experimento foi conduzido na Universidade Federal Rural de PernambucoUnidade Acadêmica de Serra Talhada, no município de Serra Talhada-PE, no período de fevereiro a abril de 2017. Foram utilizadas sementes de Piptadenia moniliformis Benth. (angico-de-bezerro).

Para a investigação da quebra da dormência, as sementes foram submetidas aos seguintes tratamentos: $\mathrm{T} 1=$ testemunha - sementes intactas; $\mathrm{T} 2$ = imersão em ácido sulfúrico concentrado por 20 minutos; T3 = imersão em hipoclorito de sódio (2,5\% de cloro ativo) por seis horas; T4 = imersão em hipoclorito de sódio por 12 horas; T5 = imersão em hipoclorito de sódio por 24 horas. Posteriormente, as sementes foram semeadas em bandejas de isopor com 128 células, utilizando como substrato a mistura solo e areia na proporção de $2: 1(\mathrm{v} / \mathrm{v})$. Os tratamentos para a quebra da dormência foram conduzidos antes de cada época de semeadura, a qual ocorreu nas seguintes datas: 22/02; 08/03 e 23/03 de 2017 .

A temperatura média do ar a $1,5 \mathrm{~m}$ da superfície do solo gramado, durante os três períodos experimentais, foram medidas em uma estação meteorológica convencional, pertencente ao Instituto Nacional de Meteorologia (INMET), localizada a $290 \mathrm{~m}$ da área experimental.

\section{Características avaliadas}

As avaliações foram realizadas, diariamente, até a estabilização da germinação, 21 dias após a semeadura, sendo avaliadas a porcentagem de emergência (PE), o índice de velocidade de emergência (IVE) conforme 
Maguire (1962) e o tempo médio de emergência (TME), seguindo Labouriau (1983).

Posteriormente, foram avaliados os comprimentos da parte aérea (CPA), a partir do coleto até a gema apical, do sistema radicular (CSR), a partir do coleto até o ápice da raiz; as plântulas normais de cada repetição foram medidas com o auxílio de uma régua graduada em $\mathrm{mm}$, com os resultados expressos em cm.plântula ${ }^{-1}$; diâmetro do coleto (DC) - mensurado com o auxílio de um paquímetro digital com precisão de $0,01 \mathrm{~mm}$, e os valores expressos em cm.plântula ${ }^{-1}$; massa seca da parte aérea (MSPA) massa seca do sistema radicular (MSR) e; massa seca total (MST) - obtida através do somatório dos valores de massa seca da parte aérea e do sistema radicular; a massa seca foi obtida através da secagem em estufa regulada a $80^{\circ} \mathrm{C}$ por 24 horas, conforme recomendações de Nakagawa (1999). Após a secagem se procedeu com a pesagem da parte aérea e do sistema radicular em balança analítica com precisão de $0,001 \mathrm{~g}$ e os resultados foram expressos em g.plântula ${ }^{-1}$. Foram determinados a relação altura da planta e diâmetro do coleto (RAD) e o índice de qualidade de Dickson (IQD), de acordo com a fórmula IQD = [massa seca total/(RAD + RPAR $)]$ (Dickson et al., 1960).

\section{Delineamento estatístico}

$\mathrm{O}$ delineamento utilizado foi $\mathrm{O}$ inteiramente casualizado, em esquema fatorial $3 \times 5$, ou seja, três épocas de semeadura e cinco tratamentos de superação de dormência, com cinco repetições de 20 sementes por tratamento. Os dados foram submetidos à análise de variância pelo teste $\mathrm{F}$ e as médias comparadas pelo teste de Tukey a 5\% de probabilidade utilizando o programa estatístico Assistat, versão 7.7.

\section{Resultados}

As médias de temperatura durante $\mathrm{o}$ período compreendido entre a data de semeadura das sementes de angico de bezerro até a estabilização da emergência das plântulas, aos 21 dias, foram as seguintes $27,4^{\circ} \mathrm{C} ; 26,9^{\circ} \mathrm{C}$ e $26,2^{\circ} \mathrm{C}$, para as épocas de semeadura realizadas nos dias 22 de fevereiro, 08 de março e 22 de março, respectivamente (Figura 1).

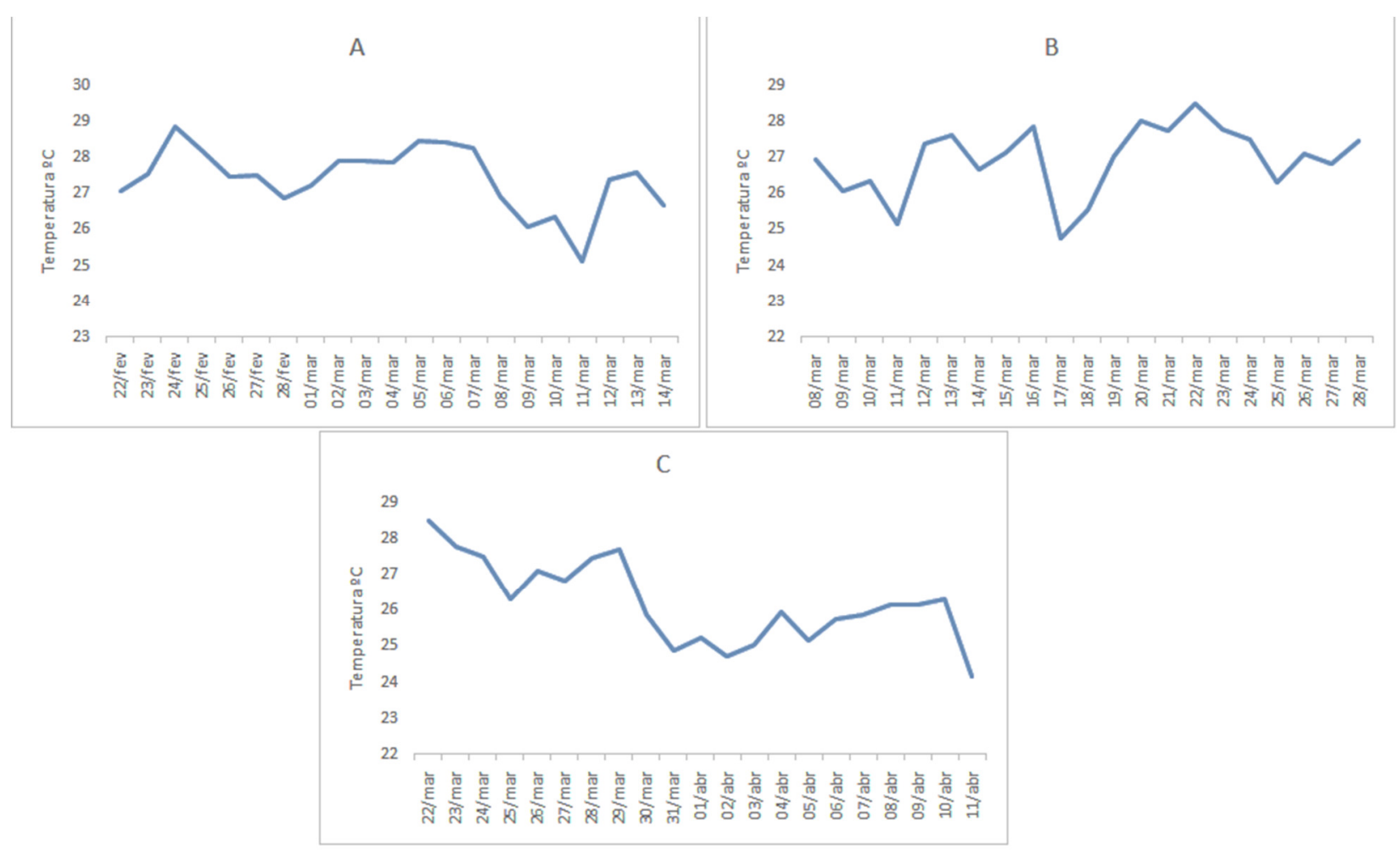

Figura 1. Média diária da temperatura durante 21 dias, após a semeadura de sementes de Piptadenia moniliformis Benth., nos dias 22 de fevereiro (A), oito (B) e 22 de março (C) de 2017. Fonte: Inmet (2017 adaptado por Joyce Naiara da Silva, 2017).

De acordo com a análise da variância (Tabela 1), observa-se interação significativa para as épocas de semeadura e os métodos de quebra da dormência para as seguintes características avaliadas: Porcentual de emergência (PE); tempo médio de emergência (TME); índice de velocidade de emergência (IVE); comprimento da parte aérea (CSR); massa seca do sistema radicular (MSSR) e relação comprimento da parte aérea e diâmetro do coleto (RAD). 
Para a porcentagem de emergência (Tabela 2) quando avaliada a época de semeadura em relação a cada tratamento de quebra da dormência, verifica-se que para as sementes intactas a melhor data de semeadura foi 22 de março. Para as sementes que foram imersas no ácido sulfúrico por 20 minutos não houve diferença estatística entre 22 de fevereiro e 22 de março, embora as sementes semeadas em 22 de fevereiro tenham mostrado uma porcentagem de emergência $19 \%$ superior àquelas semeadas em 22 de março. Para os demais tratamentos de quebra da dormência não houve diferenças estatísticas entre as épocas de semeadura.

Tabela 1. Resumo da análise de variância. $\mathrm{PE}=$ Porcentagem de emergência (\%); TME = Tempo médio de emergência (dias); IVE = Índice de velocidade de emergência; CPA = Comprimento da parte aérea (cm); CSR = Comprimento do sistema radicular $(\mathrm{cm}) ; \mathrm{DC}=$ diâmetro do coleto $(\mathrm{cm}) ;$ MSPA = Massa seca da parte aérea (g); MSSR = Massa seca do sistema radicular (g); MST = Massa seca total (g); RAD = Relação comprimento da parte aérea e diâmetro do coleto; IQD = Índice de qualidade de Dickson; ES = Época de semeadura; SD = Método de quebra da dormência.

\begin{tabular}{|c|c|c|c|c|c|c|}
\hline \multirow[b]{2}{*}{ Quadrado médio } & \multicolumn{5}{|c|}{ Fonte de variação } & \multirow{2}{*}{ CV $(\%)$} \\
\hline & ES & SD & ESxSD & Tratamento & Resíduo & \\
\hline GL & 2 & 4 & 8 & 14 & 60 & \\
\hline PE & $1296,33 * *$ & $1758,67 * *$ & $434,67 *$ & $13104,7 * *$ & 10250 & 28,89 \\
\hline TME & $3,82 *$ & $2,54 *$ & $0,19 *$ & $1,38^{\text {ns }}$ & 0,93 & 41,4 \\
\hline IVE & $1,557 * *$ & $1,707 * *$ & $0,414 * *$ & $0,947 * *$ & 0,084 & 31,86 \\
\hline CPA & $3,83 * *$ & $0,49^{\mathrm{ns}}$ & $0,43^{\mathrm{ns}}$ & $0,93 * *$ & 0,344 & 18,79 \\
\hline CSR & $13,88^{* *}$ & $0,85^{\mathrm{ns}}$ & $2,26^{*}$ & $3,52 * *$ & 0,89 & 18,48 \\
\hline DC & $0,0018 * *$ & $0,0003^{\mathrm{ns}}$ & $0,0002^{\mathrm{ns}}$ & $0,0005^{* *}$ & 0,0001 & 18,37 \\
\hline MSPA & $0,046^{* *}$ & $0,033 * *$ & $0,008^{\mathrm{ns}}$ & $0,02 * *$ & 0,005 & 36,33 \\
\hline MSSR & $0,011 * *$ & $0,001 *$ & $0,0009 *$ & $0,002 * *$ & 0,0004 & 40,63 \\
\hline MST & $0,074 * *$ & $0,046 * *$ & $0,011^{\mathrm{ns}}$ & $0,03 * *$ & 0,007 & 32,61 \\
\hline RAD & $4374,07 * *$ & $841,18 * *$ & $381,17 *$ & $1083,02 * *$ & 165,47 & 25,10 \\
\hline
\end{tabular}

** significativo ao nível de $1 \%$ de probabilidade; * significativo ao nível de $5 \%$ de probabilidade; ${ }^{\text {ns }}$ não significativo.

Tabela 2. Porcentagem de emergência (PE), tempo médio de emergência (TME) e índice de velocidade de emergência (IVE), de plântulas oriundas de sementes de Piptadenia moniliformis, submetidas a diferentes métodos de quebra da dormência e épocas de semeadura. T1 = testemunha com sementes intactas; $\mathrm{T} 2=$ imersão em ácido em ácido sulfúrico concentrado por 20 minutos; T3 = imersão em hipoclorito de sódio por 6 horas; T4 = imersão em hipoclorito de sódio por 12 horas; T5 = imersão em hipoclorito de sódio por 24 horas.

\begin{tabular}{|c|c|c|c|c|c|}
\hline \multirow[t]{2}{*}{ Épocas de semeadura } & \multicolumn{5}{|c|}{ Métodos de quebra da dormência } \\
\hline & T1 & $\mathbf{T 2}$ & T3 & T4 & T5 \\
\hline & \multicolumn{5}{|c|}{ PE (\%) } \\
\hline $22 / 02$ & $42 \mathrm{Bbc}$ & $72 \mathrm{Aa}$ & $49 \mathrm{Aab}$ & $30 \mathrm{Abc}$ & $25 \mathrm{Ac}$ \\
\hline 08/03 & $37 \mathrm{Ba}$ & $42 \mathrm{Ba}$ & $42 \mathrm{Aa}$ & $32 \mathrm{Aa}$ & $30 \mathrm{Aa}$ \\
\hline $22 / 03$ & $62 \mathrm{Aa}$ & $53 \mathrm{ABab}$ & $60 \mathrm{Aa}$ & $49 \mathrm{Aab}$ & $31 \mathrm{Ab}$ \\
\hline \multirow{2}{*}{$\mathrm{CV} \%$} & 28,89 & & & & \\
\hline & \multicolumn{5}{|c|}{ TME (dias) } \\
\hline $22 / 02$ & $3,05 \mathrm{Aa}$ & $1,49 \mathrm{Aa}$ & $1,96 \mathrm{Aa}$ & $2,14 \mathrm{Aa}$ & $2,30 \mathrm{Aa}$ \\
\hline $08 / 03$ & $3,29 \mathrm{Aa}$ & $2,13 \mathrm{Aa}$ & 2,94 Aa & $2,79 \mathrm{Aa}$ & $2,69 \mathrm{Aa}$ \\
\hline $22 / 03$ & $2,33 \mathrm{Aa}$ & $1,58 \mathrm{Aa}$ & $1,95 \mathrm{Aa}$ & $2,05 \mathrm{Aa}$ & $2,21 \mathrm{Aa}$ \\
\hline \multirow[t]{2}{*}{$\mathrm{CV} \%$} & 41,40 & & & & \\
\hline & \multicolumn{5}{|c|}{ IVE } \\
\hline $22 / 02$ & $0,68 \mathrm{Bbc}$ & $2,02 \mathrm{Aa}$ & $1,11 \mathrm{Ab}$ & $0,63 \mathrm{ABbc}$ & $0,51 \mathrm{Ac}$ \\
\hline 08/03 & $0,58 \mathrm{Ba}$ & $0,91 \mathrm{Ca}$ & $0,61 \mathrm{Ba}$ & $0,54 \mathrm{Ba}$ & $0,51 \mathrm{Aa}$ \\
\hline $22 / 03$ & $1,28 \mathrm{Aa}$ & $1,37 \mathrm{Ba}$ & $1,30 \mathrm{Aa}$ & 1,00 Aab & $0,60 \mathrm{Ab}$ \\
\hline $\mathrm{CV} \%$ & 31,86 & & & & \\
\hline
\end{tabular}

Médias seguidas de mesma letra maiúscula na coluna e minúscula na linha, não diferem significativamente entre si, em nível de $5 \%$ de probabilidade. 
Quando avaliados os métodos de quebra da dormência, verifica-se que na primeira época de semeadura, a imersão em ácido sulfúrico por 20 minutos e a imersão em hipoclorito de sódio $(2,5 \%$ de cloro ativo) por seis horas possibilitaram maior porcentagem de emergência. Por sua vez, a imersão das sementes em hipoclorito de sódio por 24 horas resultou em uma redução das plântulas normais. $\mathrm{O}$ período compreendido entre a semeadura, no dia 08 de março, até a estabilização da emergência, não apresentou diferença estatística entre os tratamentos de quebra da dormência. Por ocasião da semeadura, realizada no dia 22 de março, também não houve diferença estatística entre as sementes intactas, imersas em hipoclorito de sódio por seis horas, imersas no ácido sulfúrico e imersas em hipoclorito de sódio por 12 horas. Entretanto, esses dois últimos tratamentos, juntamente com a imersão em hipoclorito de sódio por 24 horas, mostraram, estatisticamente, os piores resultados.

Quanto ao tempo médio de emergência, não houve diferença estatística, tanto entre as datas de semeadura, como entre os tratamentos de superação de dormência.

As sementes intactas, imersas em ácido sulfúrico, imersas em hipoclorito de sódio por seis e 12 horas proporcionaram um menor índice de velocidade de emergência, quando as sementes foram semeadas no dia 08 de março, cuja temperatura média foi de $26,9^{\circ} \mathrm{C}$.
Para o comprimento da parte aérea, diâmetro do coleto, massa seca da parte aérea e massa seca total, não foi significativa a interação entre as épocas de semeadura e os métodos de quebra da dormência. Quando cada fator foi avaliado, individualmente, verificou-se que, para o CPA, a semeadura no dia 22 de março proporcionou maior comprimento da parte aérea do que as demais épocas.

Os diferentes métodos de quebra da dormência não influenciaram no comprimento da parte aérea, assim como no diâmetro do coleto (Tabela 3). As duas primeiras épocas de semeadura foram as que resultaram em maior diâmetro do coleto. O maior acúmulo de massa seca da parte aérea foi verificado nas plântulas oriundas das sementes semeadas nos dias 22 de fevereiro e 22 de março. Um maior acúmulo de massa seca total foi verificado na primeira época de semeadura. Quando avaliados os métodos de quebra da dormência, verificou-se ausência de diferença estatística entre as sementes imersas em ácido sulfúrico, as imersas no hipoclorito de sódio por seis horas e as sementes intactas, embora essas últimas, juntamente com as que ficaram imersas por 12 e 24 horas no hipoclorito de sódio, tenham resultado em plântulas com menor massa seca da parte aérea.

Tabela 3. Comprimento da parte aérea (CPA); diâmetro do coleto (DC); massa seca da parte aérea (MSPA); massa seca total (MST) de plântulas oriundas de sementes de Piptadenia moniliformis, submetidas a diferentes métodos de quebra da dormência e épocas de semeadura. T1 = testemunha - sementes intactas; T2 = imersão em ácido em ácido sulfúrico concentrado por 20 minutos; T3 = imersão em hipoclorito de sódio por 6 horas; T4 = imersão em hipoclorito de sódio por 12 horas; T5 = imersão em hipoclorito de sódio por 24 horas.

\begin{tabular}{ccccc}
\hline Épocas de semeadura & CPA $(\mathbf{c m})$ & DC $(\mathbf{c m})$ & MSPA $(\mathbf{g})$ & MST $(\mathbf{g})$ \\
\hline $22 / 02$ & $2,85 \mathrm{~b}$ & $0,069 \mathrm{a}$ & $0,24 \mathrm{a}$ & $0,311 \mathrm{a}$ \\
$08 / 03$ & $2,94 \mathrm{~b}$ & $0,067 \mathrm{a}$ & $0,16 \mathrm{~b}$ & $0,20 \mathrm{~b}$ \\
$22 / 03$ & $3,57 \mathrm{a}$ & $0,053 \mathrm{~b}$ & $0,22 \mathrm{a}$ & $0,24 \mathrm{~b}$ \\
Métodos de quebra da dormência & & & & \\
\hline T1 & $3,31 \mathrm{a}$ & $0,059 \mathrm{a}$ & $0,21 \mathrm{abc}$ & $0,26 \mathrm{ab}$ \\
T2 & $3,12 \mathrm{a}$ & $0,058 \mathrm{a}$ & $0,254 \mathrm{a}$ & $0,31 \mathrm{a}$ \\
T3 & $3,22 \mathrm{a}$ & $0,066 \mathrm{a}$ & $0,247 \mathrm{ab}$ & $0,30 \mathrm{a}$ \\
T4 & $3,12 \mathrm{a}$ & $0,064 \mathrm{a}$ & $0,174 \mathrm{bc}$ & $0,22 \mathrm{~b}$ \\
T5 & $2,83 \mathrm{a}$ & $0,068 \mathrm{a}$ & $0,143 \mathrm{c}$ & $0,18 \mathrm{~b}$ \\
\hline
\end{tabular}

Médias seguidas pela mesma letra minúscula nas colunas não diferem entre si pelo teste de Tukey ao nível de $5 \%$ de probabilidade.

Considerando a média do comprimento do sistema radicular das plântulas oriundas das sementes intactas, imersas em hipoclorito de sódio por seis e 12 horas, não houve diferença estatística entre as épocas de semeadura (Tabela 4). Por sua vez, as plântulas provenientes das sementes imersas em ácido sulfúrico e em hipoclorito de sódio por 24 horas, tratamentos que não diferiram entre si, apresentaram as menores médias quando as sementes foram semeadas em 22 de março.

Quanto às épocas de semeadura, não houve diferença estatística entre as sementes intactas e as 
que foram imersas em hipoclorito de sódio por 12 horas, para o acúmulo de massa seca do sistema radicular. As plântulas provenientes das sementes submetidas aos tratamentos por imersão em ácido sulfúrico e imersão em hipoclorito de sódio por seis e 24 horas, apresentaram, na primeira época de semeadura ( 22 de fevereiro) e na última ( 22 de março), maior e menor acúmulo do MSSR, respectivamente.

Tabela 4. Comprimento (CSR) e massa seca (MSSR) do sistema radicular de plântulas oriundas de sementes de Piptadenia moniliformis, submetidas a diferentes métodos de quebra da dormência e épocas de semeadura. $\mathrm{T} 1$ = testemunha - sementes intactas; $\mathrm{T} 2$ = imersão em ácido em ácido sulfúrico concentrado por 20 minutos; $\mathrm{T} 3$ = imersão em hipoclorito de sódio por 6 horas; $\mathrm{T} 4$ = imersão em hipoclorito de sódio por 12 horas; $\mathrm{T} 5=$ imersão em hipoclorito de sódio por 24 horas.

\begin{tabular}{|c|c|c|c|c|c|}
\hline \multirow[b]{3}{*}{ Épocas de semeadura } & \multicolumn{5}{|c|}{ CSR (cm) } \\
\hline & \multicolumn{5}{|c|}{ Métodos de quebra da dormência } \\
\hline & T1 & $\mathbf{T 2}$ & $\mathbf{T 3}$ & $\mathrm{T4}$ & T5 \\
\hline $22 / 02$ & $5,03 \mathrm{Aa}$ & $5,56 \mathrm{Aa}$ & $5,08 \mathrm{Aa}$ & $4,94 \mathrm{Aa}$ & $6,44 \mathrm{Aa}$ \\
\hline $08 / 03$ & 5,28 Aa & $5,13 \mathrm{ABa}$ & $5,76 \mathrm{Aa}$ & $6,21 \mathrm{Aa}$ & $5,85 \mathrm{Aa}$ \\
\hline $22 / 03$ & 4,33 Aa & $3,77 \mathrm{Ba}$ & 4,89 Aa & 4,94 Aa & $3,32 \mathrm{Ba}$ \\
\hline \multirow[t]{3}{*}{$\mathrm{CV} \%$} & 18,48 & & & & \\
\hline & \multicolumn{5}{|c|}{$\operatorname{MSSR}(\mathbf{g})$} \\
\hline & \multicolumn{5}{|c|}{ Métodos de quebra da dormência } \\
\hline Épocas de semeadura & $\mathbf{T} 1$ & $\mathbf{T 2}$ & $\mathbf{T 3}$ & $\mathrm{T4}$ & T5 \\
\hline $22 / 02$ & $0,059 \mathrm{Abc}$ & 0,09 Aab & $0,096 \mathrm{Aa}$ & $0,051 \mathrm{Ac}$ & $0,052 \mathrm{Ac}$ \\
\hline 08/03 & $0,058 \mathrm{Aa}$ & $0,043 \mathrm{Ba}$ & $0,047 \mathrm{Ba}$ & $0,042 \mathrm{Aa}$ & $0,041 \mathrm{ABa}$ \\
\hline $22 / 03$ & $0,032 \mathrm{Aa}$ & $0,027 \mathrm{Ba}$ & $0,027 \mathrm{Ba}$ & $0,032 \mathrm{Aa}$ & $0,018 \mathrm{Ba}$ \\
\hline $\mathrm{CV} \%$ & 40,63 & & & & \\
\hline
\end{tabular}

Médias seguidas de mesma letra maiúscula na coluna e minúscula na linha, não diferem significativamente entre si, em nível de 5\% de probabilidade.

Quando avaliada a interferência das épocas de semeadura sobre os métodos de quebra da dormência, observa-se que as sementes intactas, imersas em ácido sulfúrico e em hipoclorito de sódio por seis horas resultaram em plântulas com maior RAD (Tabela 5) quando a semeadura ocorreu em 22 de março, para os demais tratamentos não houve diferença entre as épocas. Verifica-se, também, que não houve diferença significativa entre os métodos de quebra da dormência para as duas primeiras épocas de semeadura, por sua vez, na última época ( 22 de março), as sementes intactas, imersas em ácido sulfúrico e em hipoclorito de sódio por seis horas, proporcionaram melhores resultados em relação as que foram imersas em hipoclorito de sódio por 12 e 24 horas.

Tabela 5. Relação comprimento da parte aérea e diâmetro do coleto (RAD) de plântulas oriundas de sementes de Piptadenia moniliformis, submetidas a diferentes métodos de quebra da dormência e épocas de semeadura. $\mathrm{T} 1$ = testemunha - sementes intactas; $\mathrm{T} 2$ = imersão em ácido em ácido sulfúrico concentrado por 20 minutos; T3 = imersão em hipoclorito de sódio por 6 horas; T4 = imersão em hipoclorito de sódio por 12 horas; T5 = imersão em hipoclorito de sódio por 24 horas.

\begin{tabular}{|c|c|c|c|c|c|}
\hline \multirow{3}{*}{ Épocas de semeadura } & \multicolumn{5}{|c|}{ Métodos de quebra da dormência } \\
\hline & $\mathbf{T 1}$ & T2 & T3 & T4 & T5 \\
\hline & \multicolumn{5}{|c|}{ RAD } \\
\hline $22 / 02$ & $38,29 \mathrm{Ba}$ & $42,23 \mathrm{Ba}$ & $44,47 \mathrm{Ba}$ & $47,91 \mathrm{Aa}$ & $36,72 \mathrm{Aa}$ \\
\hline $08 / 03$ & $55,33 \mathrm{Ba}$ & $51,88 \mathrm{Ba}$ & $38,74 \mathrm{Ba}$ & $44,01 \mathrm{Aa}$ & $37,17 \mathrm{Aa}$ \\
\hline $22 / 03$ & 86,48 Aa & $72,16 \mathrm{Aab}$ & $69,86 \mathrm{Aab}$ & $57,42 \mathrm{Abc}$ & 45,99 Ac \\
\hline CV\% & 25,10 & & & & \\
\hline
\end{tabular}

Médias seguidas de mesma letra maiúscula na coluna e minúscula na linha, não diferem significativamente entre si, em nível de 5\% de probabilidade.

\section{Discussão}

Quando avaliada a época de semeadura para o porcentual de emergência, observou-se que para as sementes intactas a melhor data de semeadura foi a do dia 22 de março, pois à partir da mesma até a estabilização da emergência, as 
temperaturas mantiveram-se menores (Figura 1); segundo Riley (1981) temperaturas mais elevadas provocam diminuição do suprimento de aminoácidos livres, da síntese protéica e das reações anabólicas, podendo desnaturar proteínas e alterar a permeabilidade das membranas. Para as semente imersas no ácido sulfúrico observou-se que embora não houve-se diferença estatística entre as semeaduras realizadas nos dias 22 de fevereiro e 22 de março, a primeira data proporcionou um porcentual maior. A alternância de temperatura pode resultar em melhores condições de germinação para sementes de algumas espécies tropicais, como constataram Gomes \& Bruno (1992) para Bixa orellana e Castellani \& Aguiar (1998) para Trema micrantha. As sementes que respondem à alternância de temperatura apresentam mecanismos enzimáticos que funcionam em diferentes temperaturas (VasquezYanes \& Orozco-Segovia, 1987) e, segundo Borges \& Rena (1993), essa resposta corresponde, provavelmente, a uma adaptação às flutuações naturais do ambiente. Para os métodos de quebra da dormência, observa-se que as sementes que foram imersas por 24 horas em hipoclorito de sódio apresentaram menores valores de plântulas normais, provavelmente o poder corrosivo da hipoclorito de sódio juntamente com o longo período de imersão, causaram a morte de grande parte das sementes.

Apesar da ausência de diferença estatistica entre as épocas de semeadura, as sementes semeadas em 08 de março demoraram mais tempo para originarem plântulas normais, isso pode ter ocorrido devido a uma maior oscilação de temperatura verificada nessa época (Figura 1). Para os métodos de superação de dormência também não houve diferença para o tempo médio de emergência, Alves et al. (2000) verificaram que as sementes de Bauhinia monandra e B. ungulata, submetidas a imersão em ácido sulfúrico por 20 minutos, demoraram 11 e 18 dias para formarem plântulas normais, respectivamente. Araújo et al. (2013), trabalhando com Leucaena leucocephala (Lam.), não encontraram diferenças entre os tratamentos impostos às sementes, obtendo uma média de três dias para a formação das plântulas. $\mathrm{O}$ tempo médio de germinação é importante para se avaliar a rapidez de ocupação de uma espécie em uma comunidade vegetal (Ferreira et al., 2001).

Os resultados encontrados para o IVE quando as sementes foram semeadas no dia 08 de março, cuja temperatura média foi de $26,9^{\circ} \mathrm{C}$, corroboram com os encontrados para a característica tempo médio de emergência. Mello $\&$ Barbedo (2007) verificaram que, quanto mais elevada a temperatura para a germinação de sementes de Caesalpinia echinata (Fabaceae), mais concentrada temporalmente em torno do número médio de dias para germinar. Considerando a semeadura no dia 22 de fevereiro, as sementes submetidas ao ácido sulfúrico foram as que apresentaram um maior IVE em relação às sementes intactas e aquelas imersas no hipoclorito de sódio por 12 e 24 horas. Por sua vez, para a semeadura em 08 de março, não houve diferenças entre os tratamentos, na última data de semeadura as sementes imersas no hipoclorito de sódio por 12 e 24 horas foram as que resultaram em menores índices. As sementes que apresentam os maiores índices, são as conseguem originar o maior número de plântulas por dia (Nakagawa, 1994). Conforme Bewley \& Black (1994), a temperatura afeta tanto a capacidade como a velocidade de germinação. As sementes têm a capacidade de germinar dentro de uma determinada faixa de temperatura, característica para cada espécie, mas o tempo necessário para se obter a percentagem máxima de germinação é dependente da temperatura. Rodrigues et al. (2008), submetendo sementes de Acacia magium a imersão em ácido sulfúrico por 15, 30, 60 e 90 minutos, e em água fervente por 15, 30 e 60 minutos, verificaram que, para a imersão em ácido, houve valores de IVE entre 16,17 e 23,76 dias; para a imersão em água fervente os valores variaram de 11,32 a 17,37 dias, em ordem crescente de tempo de imersão

A semeadura no dia 22 de março, cuja média da temperatura foi menor, propiciou maior comprimento da parte aérea do que as demais épocas, indicando que o desenvolvimento da parte aérea das plântulas foi mais sensível às variações da temperatura do que o do sistema radicular e que há diferenças de requerimento de temperatura para o desenvolvimento das diferentes partes da plântula (Bracalion et al., 2008). A diferença de $1^{\circ} \mathrm{C}$ na temperatura, durante $\mathrm{o}$ teste de germinação, provavelmente pode ter efeito desprezível na porcentagem de germinação, mas essa diferença na temperatura poderá proporcionar efeitos consideráveis no crescimento das plântulas, alterando seu comprimento e/ou sua massa seca (Nakagawa, 1999).

Os tratamentos de imersão em ácido sulfúrico e em hipoclorito de sódio por 6 horas propiciaram um maior acúmulo de massa seca da parte aérea e total, comportamento semelhante foi verificado por Brito et al. (2014) que, ao trabalharem com sementes de Mimosa ophthalmocentra, verificaram que tanto a massa seca da parte aérea como a do sistema radicular apresentaram diferenças significativas entre os tratamentos de superação de dormência utilizados, sendo que os tratamentos T4 e T5 (imersão em 
ácido sulfúrico por 5 e 10 minutos, respectivamente) não diferiram entre si, e foram superiores aos tratamentos $\mathrm{T} 1$ (testemunha); T2 (imersão em água ambiente por 12 horas); T3 (imersão em hipoclorito de sódio por 6 horas) e T6 (imersão em soda cáustica $20 \%$ por 10 minutos), os quais não diferiram entre si. Sementes de Mimosa caesalpiniaefolia submetidas a tratamentos prégerminativos com ácido sulfúrico concentrado por 10 ou 13 min., originaram plântulas com maior conteúdo de massa seca (Bruno et al., 2001). Também, Sampaio et al. (2001) verificaram maior conteúdo de massa em plântulas de Bowdichia virgilioides com a imersão das sementes em ácido sulfúrico concentrado por períodos entre 8 e 11 $\min$.

A última época de semeadura propiciou uma maior relação diâmetro altura da plântula, quanto menor o diâmetro do coleto maior será a RAD, causando um desequilíbrio entre a média de altura da parte aérea e o diâmetro do colo. Portanto, quanto menor for o valor da RAD, melhor será a qualidade da muda, pois demonstra um bom equilíbrio entre as partes da planta, o que refletirá em maior resistência às condições adversas no campo (Gomes et al, 2002). O índice da relação comprimento da parte a diâmetro do coleto (RAD) para todas os tratamentos foram maiores que 10, padrão recomendado por Birchler et al. (1998). A altura da parte aérea combinada com o diâmetro do coleto constitui um dos mais importantes parâmetros morfológicos para estimar o crescimento das mudas após o plantio definitivo no campo. O valor resultante da divisão da altura da parte aérea pelo seu respectivo diâmetro do coleto exprime o equilíbrio de crescimento (Carneiro, 1995), também denominado de quociente de robustez, sendo considerado um dos mais precisos, pois fornece informações do quanto está delgada a muda (Johnson \& Cline, 1991).

\section{Conclusão}

As épocas de semeadura pouco influenciaram na expressão das características relacionadas à germinação, entretanto as sementes sem qualquer tratamento de superação de dormência germinaram melhor na última época, cuja temperatura foi ligeiramente mais amena do que a segunda.

A eficiência dos métodos de superação de dormência variou com a época de semeadura, entretanto tanto as sementes imersas em ácido sulfúrico por 20 minutos como em hipoclorito de sódio por seis horas, proporcionaram os melhores resultados.

Para os parâmetros relacionados ao desenvolvimento inicial das plântulas, não houve diferença do comprimento da parte aérea e do sistema radicular para os métodos de superação de dormência, já com relação as épocas de semeadura, a última época, cuja temperatura foi mais amena, proporcionou um maior comprimento da parte aérea, entretanto, a variação de temperatura observada entre as épocas de semeadura não resultou em diferenças para o comprimento do sistema radicular das plântulas.

\section{Referências}

ALVES, M. C. S.; MEDEIROS FILHO, S.; ANDRADE NETO, M.; TEÓFILO, E. M. 2000. Superação de dormência em sementes de Bauhinia monandra Britt. e Bauhinia ungulata L. Cesalpinoideae. Revista Brasileira de Sementes, v. 22, n. 2, p. 139-144.

ARAÚJO NETO, J. C.; AGUIAR, I. B.; FERREIRA, V. M. 2003. Efeito da temperatura e da luz na germinação de sementes de Acacia polyphylla DC. Revista Brasileira de Botânica, v. 26, n. 02, p. 249-256.

ARAÚJO, A. V.; FREIRE, C. S.; PINTO, M. A. D. S. C.; BARBOZA, V. R. S. 2013. Métodos de superação de dormência para a produção de mudas de Leucaena leucocephala (Lam.) de Wit. Enciclopédia Biosfera, v. 9, n. 7, p. 1898-1908.

BEWLEY, J. D.; BLACK, M. 1994. Seeds: physiology of development and germination. 2.ed. New York: Plenum Press. 445p.

BORGES, E. E. L.; RENA, A. B. 1993. Germinação de sementes. In: AGUIAR, I. B.; PIÑA-RODRIGUES, F. C. M.; FIGLIOLIA, M. B. Sementes florestais tropicais. Brasília: Associação Brasileira de Tecnologia de Sementes, Comitê Técnico de Sementes Florestais, pp. 83-135.

BRACALION, P. H. S.; NOVEMBRE, A. D. L. C; RODRIGUES, R. R.; CHAMMA, H. M. C. P. 2008. Efeito da luz e de diferentes temperaturas na germinação de sementes de Heliocarpus popayanensis L. Revista Árvore, v. 32, n. 2, p. 225232.

BRITO, A. S.; PINTO, M. A. D. S.; ARAÚJO, A. V.; SOUZA, V. N. 2014. Superação de dormência em Mimosa ophthalmocentra Mart. Ex Benth. Enciclopédia Biosfera, v. 10, n. 18, p. 2792.

BRUNO, R. L. A. ALVES, E. U.; OLIVEIRA, A. P.; PAULA, R. C. 2001. Tratamentos prégerminativos para superar a dormência de sementes 
de Mimosa caesalpiniaefolia Benth. Revista Brasileira de Sementes, v. 23, n. 2, p. 136-143.

CARNEIRO, J. G. A. 1995. Produção e controle de qualidade de mudas florestais. Curitiba: UFPR/FUPEF, 451p.

CASTELLANI, E. D.; AGUIAR, L. B. 1998. Condições preliminares para a germinação de sementes de candiúba (Trema micrantha (L.) Blume). Revista Brasileira de Engenharia Agrícola e Ambiental, v. 2, n. 1, p. 80-3.

FERREIRA, A. G.; CASSOL, B.; ROSA, S. G. T.; SILVEIRA, T. S.; STIVAL, A. L.; SILVA, A. A. 2001. Germinação de sementes de Asteraceae nativas no Rio Grande do Sul, Brasil. Acta Botanica Brasilica, v. 15, n. 2, p. 231-242.

GOMES, S. M. S.; BRUNO, R. L. A. 1992. Influência da temperatura e substratos na germinação de sementes de urucum (Bixa orellana L.). Revista Brasileira de Sementes, v. 14, n. 1, p. 47-50.

JOHNSON, J. D.; CLINE, P. M. 1991. Seedling quality of southern pines. In: DUREYA, M. L.; DOUGHERTY, P. M. (Eds.). Forest regeneration manual. Dordrecht: Kluwer Academic Publishers, pp. 143-162.

LORENZI, H. 2002. Árvores brasileiras: manual de identificação e cultivo de plantas arbóreas do Brasil. São Paulo: Nova Odessa. 197p.

MELLO, J. I. O.; BARBEDO, C. J. 2007. Temperatura, luz e substrato para germinação de sementes de pau-brasil (Caesalpinia echinata
Lam., Leguminosae - Caesalpinioideae). Revista Árvore, v. 31, n. 4, p. 645-655.

NAKAGAWA, J. 1994. Testes de vigor baseados na avaliação das plântulas. In: VIEIRA, R. D.; CARVALHO, N. M. Testes de vigor em sementes. Jaboticabal: FUNEP, pp. 49-85.

NAKAGAWA, J. 1999. Testes de vigor baseados no desempenho das plântulas. In: KRZYZANOWSKI， F. C.; VIEIRA， R. D.; FRANÇA NETO, J. B. (Eds.) Vigor de sementes: conceitos e testes. Londrina: ABRATES, pp. 2.12.24 .

RILEY, G.J.P. 1981. Effects of high temperature on protein synthesis during germination of Maize (Zea mays L.). Planta, v. 15, n. 1, p. 75-80.

RODRIGUES, A. P. D'. C.; KOHI, M. C.; PEDRINHO, D. R.; ARIAS, E. R. A.; FAVERO, S. 2008. Tratamentos para superar a dormência de sementes de Acacia mangium Willd. Acta Scientiarum Agronomy, v. 30, n. 2, p. 279-283.

SAMPAIO, L. S. V.; PEIXOTO, C. P.; PEIXOTO, M. F. S. P.; COSTA, J. A.; GARRIDO, M. S.; MENDES, L. N. 2001. Ácido sulfúrico na superação da dormência de sementes de sucupira preta (Bowdichia virgilioides H.B.K. - Fabaceae). Revista Brasileira de Sementes, v. 23, n. 1, p. 184190.

VASQUEZ-YANES, C.; OROZCO-SEGOVIA, A. 1987. Fisiología ecológica de las semillas en la Estación de Biología tropical "Los Tuxilas", Veracruz, México. Revista de Biología Tropical, v. 35, p. 85-96. 